\title{
MASON RebeLand: An Agent-Based Model of Politics, Environment, and Insurgency
}

\author{
Claudio Cioffi-Revilla and Mark Rouleau \\ Center for Social Complexity, Krasnow Institute for Advanced Study \\ George Mason University, Fairfax, VA 22030, U.S.A. \\ E-mail: $\{$ ccioffi,mrouleau $\} @$ gmu.edu \\ Proceedings of the Human Behavior-Computational Modeling and Interoperability Conference 2009 \\ HB-CMI-09, Joint Institute for Computational Science, Oak Ridge National Laboratory, Oak Ridge, \\ Tennessee, U.S.A., June 23-24, 2009
}

\begin{abstract}
Social simulation models from computational social science are beginning to provide significant advances in terms of implementing more complex social, human, and natural dynamics that are characteristic of how realworld countries operate. The MASON RebeLand model presents three innovations: (1) an explicit polity model with politically complete structure and processes; (2) social and natural model components within an integrated socionatural system; and (3) generative dynamics where insurgency and the state of the polity (stable, unstable, failing, failed, recovering) occur as emergent phenomena under a range of social and environmental conditions. Earlier agentbased models (ABMs) on similar topics have been useful in covering parts of RebeLand's scope. Three scenarios are demonstrated, showing stable, unstable, and failing polity conditions. The MASON computational system also permits additional experiments and extensions.
\end{abstract}

Index Terms-Conflict modeling, agent-based modeling, social simulation, Eastern Africa, coupled socio-natural systems.

\section{INTRODUCTION: MOTIVATION AND BACKGROUND}

The state of any given polity-in every country, ancient or contemporary, universally-depends on multiple internal and external factors. Exactly how the state of a polity or its political stability is affected by internal (endogenous) or environmental (exogenous) processes, such as changing conditions in its economy, demography, culture, natural environment, climate, or combined socionatural pressures? This paper presents an agent-based model of a polity with structure and process based on contemporary political science concepts and principlesi.e., a political system specifically composed of a geographically situated society with a system of government that produces policies to address public issues. Moreover, aggregate or collective features such as public moods, domestic political instability, insurgency, and state failure are generated endogenously as emergent phenomena from individual (actor-level) and institutional behaviors. Both the polity and its natural environment in this model can be extended in a number of research directions.

Stability and instability have two meanings:

1) In the classical dynamical sense of Ljapunov and systems theory (the meaning used here), political stability means that a polity is stable if and only if it can withstand various forms of stress (social, economic, political, environmental) with or without violence. Stability and lack of violence are separate dimensions. Stability in this sense is a deep dynamical property.

2) Political stability also means the lack of political violence. Conversely, political instability in this second sense means (i.e., is synonymous with) the occurrence of public violence in a given polity. Accordingly, stability in this second common sense is an observed behavior unrelated to deeper dynamical properties.

Previous empirical studies have identified a number of variables associated with political instability in the former sense. Relative deprivation (Gurr 1970) is a cause of civil unrest and revolutionary movements function as outlets for the general population's frustration with the current social structure of the state, leading citizens to use violence to realign this structure to attain expected social benefits (Morrison 1973). This intuitive notion of political instability remains important despite criticisms (Gurney \& Tierney 1982). The weaknesses of relative deprivation theory have led to the 'culturalist' argument: ethnic or religious differences as the source of political 
instability.

Two recent studies question the 'cultural' argument. Opportunity to rebel is as important as motivation for rebellion (Fearon \& Laitin 2003), since the probability of civil unrest does not depend on cultural fractionalization or economic disparity, but rather on State attributes that favor insurgency (rough terrain, large populations, and financial and/or bureaucratic weakness). This "opportunity" argument focused on insurgency finance through lootable resources (Collier \& Hoeffler 1998, 2004) is also consistent with the political economy of rogue organizations that compete with the state (Mouseau 2006). Political instability is more likely in states with weak institutional structures and highly accessible natural resource endowments with high marketability (diamonds, gold). These studies emphasize the dichotomy between state and rebel capacity in regards to political instability. Other recent work also supports the 'opportunity'-based argument for political instability albeit with an ethnic conflict slant (Cederman \& Girardin 2007), consistent with earlier views (Ferguson \& Mansbach 1996) on competing polities. Others highlight the failure of institutional structures, particularly those of partial democracies, as means and motivation for political instability (King \& Zeng 2001). RebeLand also draws on other extant ideas (e.g., Kalyvas 2000).

Early models of insurgency based on system dynamics are reviewed in Cioffi \& Rouleau (2009). Most computational research in civil unrest is now undertaken using the ABM approach, with relatively fewer models using the systems dynamics approach (Choucri et al. 2007), emphasizing "bottom-up" processes in the development of civil unrest (Fearon\& Laitin 2003; Cederman \& Girardin 2007; DeRouen \& Sobek 2004; Kalyvas 2006).

Epstein (2002) has applied conflict mechanisms of Sugarscape to produce one of the first civil violence models, investigating the emergence of rebellion and ethnic cleansing behavior as a product of the perception of police force numbers and intervention tactics at the level of individual agents. Unlike early state-level ABM simulations incorporating concepts of nationalism and domestic culture (e.g., the GeoSim model, Cederman 2003; Cioffi-Revilla \& Gotts, 2003) or collective identity models (Lustick 2000), the Sugarscape/Civil War model (Epstein 2002) takes a highly magnified approach to examine the citizen-based impetus for rebellion as opposed to simply outlining the effects of domestic unrest upon international relations. Similarly, the ISAAC and EINSTein models (Ilachinski 2004) have used a similar technique to model combat at the level of the individual soldier. These models were also the first to rigorously apply insights from complex adaptive systems, such as the notion of self-organization, to replicate the non-linear dynamics found in an irregular warfare environment.

Current civil unrest models extend earlier models by introducing some form of natural or social complexity. IRUBA (Doran 2005) — a meso-scale replication of Epstein's civil violence model at the level of provincial conflict-uses simple geographic features (terrain and spatial distribution of rebel resources) and military forces to test various insurgency and counterinsurgency tactics. Bennett's (2009) most recent work in this same area leverages aspects of social complexity, such as the distinction between the perception of fear and anger in domestic populations. REsCape (Bhavnani et al. 2008) provides the first representation of selected institutions within a repressive state. These models use social networks (i.e., media), weather events (i.e., tsunami), social identities (i.e. ethnicities), and political/economic freedom to explore the development of civil unrest. RebeLand builds on these extant efforts in the most recent generation of computational models.

RebeLand is a combination of the meso- and micro-level strengths of its predecessors. It aims to model sociopolitical behaviors within a framework of coupled socionatural complexity.

\section{THE MASON REBELAND MODEL}

RebeLand addresses two research questions: (1) How does a polity respond to various levels of societal stress and governmental performance? (2) How can insurgency, domestic political instability, or even state failure in some extreme cases emerge as a bottom-up phenomenon in the life of a polity?

The simulated model polity itself is spatially situated (geography is a constituent, not optional, feature of every country in the world) and has a system of government that conforms to canons of political science. The latter requirement means that the governmental architecture must be recognizable to a political scientist, not implicit or arbitrary. Additionally, following a complexity perspective, emergent phenomena must be generated by the interaction of agents in a "bottom-up" way; it must not be hard-wired.

The RebeLand model is written in MASON (Luke et al. 
2005 ) in the Java programming language ${ }^{1}$. An important design feature of MASON is its original architecture in terms of completely separating computation from visualization, thus increasing speed and other desirable features needed in this investigation (e.g., data fields for individual cognitive structures in subsequent versions; see Discussion). Other MASON models with spatial orientation and interactive societal and natural environments are described elsewhere (cf., Cioffi-Revilla \&Rouleau 2009) along with additional details on RebeLand.

\section{A. Model structure}

Figure 1 shows a "map" view of RebeLand as a polity or country that is situated in a natural environment, with a basic socio-natural system or socio-ecological ontology. The socio-natural interaction is also intentionally simple, reflecting mostly environmental effects on the polity. (Subsequent research will also examine long-term anthropogenic effects on the environment.)

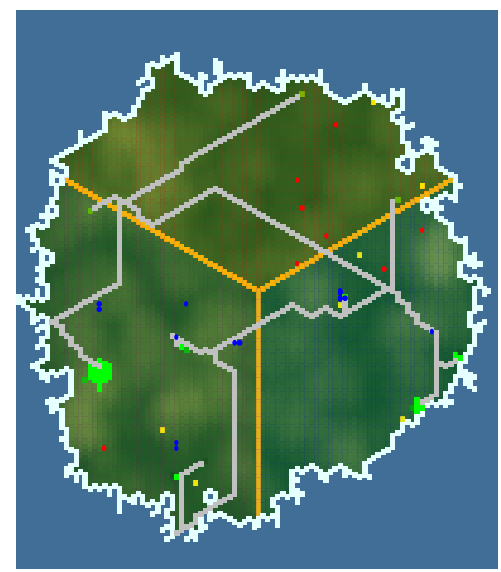

Fig. 1. Map of RebeLand Island showing its main natural and social features. Legend: Cities are shown in green, natural resources in yellow, and rebel and government forces in red and blue, respectively. Roads and provincial boundaries are in gray and yellow, respectively. Physical topography is shown on a green-tone scale and the island is surrounded by ocean. Source: Prepared by the authors.

Environmental component. The RebeLand environment consists of terrain and a simple weather system. In turn, the terrain consists of physical topography and land cover. Additionally, generic natural resources (e.g., oil, diamonds, gold, or similar; yellow dots in Figure 1) are distributed over the terrain. Additional features (e.g., hydrology) can also be added.

\footnotetext{
${ }^{1}$ See http://cs.gmu.edu/ eclab/projects/mason/
}

Political component. Following a political science orien- ${ }^{3}$ tation (Cioffi-Revilla 2009), the RebeLand polity consists of a society and a system of government for dealing with public issues through public policies (Fig. 2). Government produces policies for addressing public issues that affect society. Under some conditions, the society can also generate insurgents that interact with government forces.

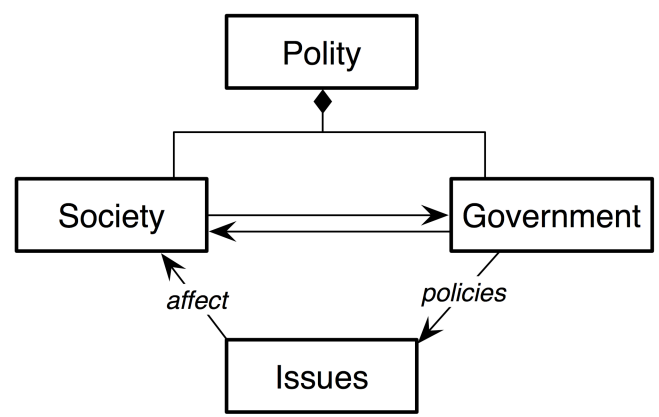

Fig. 2. High-level UML class diagram of a simple polity such as that represented in RebeLand. Government manages public issues through policies, as detailed in Figure 2. Source: Cioffi-Revilla 2009.

There are three provinces in RebeLand (see Fig. 1 earlier), each with a subset of population centers, resources, roads, and other features of the country. Provincial boundaries were drawn to produce approximately equal size, but these and other features can be easily modified. Population centers are distributed in the island according to a Zipf distribution. A system of roads connects population centers with natural resource locations. Roads were drawn using a gradient-driven algorithm based distance and terrain (see below).

Primary agents consist of the general population, cities, and the state. Cities represent local public administration organizations, whereas the state represents the system of government of the overall polity. Secondary agents consist of rebels generated from the general population under a range of conditions (discussed below), rebel groups, and government forces representing police and military units. Rebels are supported by rebel group organizations that support them and fund alternative policies that rival official state policies. Government forces seek to destroy insurgents by attacking them and guarding the home city.

\section{B. Dynamics}

From a high-level perspective, and importantly, RebeLand aims to operate as all polities do: At any given 
time, a public issue affects the population, which causes societal stress. In response, government formulates and implements policies that aim to eliminate or mitigate stress on the population. Government operates with capacity derived from revenues produced by taxes (public finance), and taxes are paid by the population based on disposable income derived from labor. Normally, state capacity is sufficient to deal with public issues, but various factors can contribute to instability and even political change-just like in real-world polities.

1) Initialization: The RebeLand simulation begins by generating a random island environment. Starting from the center-most cell, a greedy algorithm selects a predefined number of contiguous grid cells that will serve as the island's land cells. Next, a terrain generation algorithm makes a series of random elevation changes conditioned by a user defined parameter of three possible natural environments: grassland, hills, and mountains. The simulation then randomly distributes resources (i.e., oil, gold, diamonds) throughout the island and calculates their profitability based on current market value, amount of resource present, distance to nearest shoreline ("tradeability"), and distance to the next nearest resource. If a city center cell is overpopulated, a random neighboring cell is chosen and the remaining population inhabits this cell with this process continuing until all general population agents belonging to this city have been placed onto the map. An A* algorithm draws a "shortest path" road network between cities, accounting for both elevation changes and linear distances.

2) Main Simulation Loop and Typical Simulation Run: The RebeLand main simulation loop conforms to the known system and processes of a polity based on contemporary political science theory (Cioffi-Revilla 2009). Issues can originate within the society itself (e.g., inflation increasing; endogenous to the society) or in the environment (drought or other ecological change or disaster affecting agricultural productivity; exogenous to the society). Local city governments produce policies to deal with public issues. If population dissatisfaction increases due to stress, insurgents may be generated from the population. If so, then government generates counterinsurgency units to combat and manage the insurgency-if and when it is capable. Insurgency is also a source of public issue and stress on the population, along with other sources such as the environment and/or endogenous social processes. The simulation schedule activates agents at random and, once activated, each agent both performs expected tasks and responds to its current environment. Depending on their social condition, general population agents will adjust their satisfaction and regime support values appropriately. City government agents tax the general population to build revenue and distribute welfare benefits. The last of the non-mobile agents, the state agent, simply directs a share of the remaining city revenue towards the most pressing issues left unsupported.

\section{Computational Demonstration Results}

The first scenario represents a stable political situationin the sense defined above-where government manages public issues and society is satisfied (Switzerland). The second scenario is a significantly more contentious political situation where public issues produce extensive societal discontent, dissent, and incipient insurgency which, however, is managed by government (Mexico, Russia, Columbia). The third scenario is an unstable political situation where the insurgency manages to topple the government, bringing about state failure (Somalia).

For each scenario we report three simulation results using the time-series graphs shown in Figures 3-5:

- (Sub-figure a) General population needs in terms of average perceived wealth (green), average food level (blue), and average security value (red);

- (Subfigure b) Population support for government (blue) vs. support for rebels (red), representing key dimensions of public opinion; and

- (Subfigure c) Trends in state capacity in terms of number of current public issues being managed (red), number of non-security issues (blue), and number of current polices (green).

\section{A. Stable scenario (Fig. 3)}

Figure 3 shows results from the first scenario or stable regime, where the general population is happy in terms of average perceived wealth, eating well and feeling secure (Fig. 3a). Concurrently, levels of support for government are high and, conversely, support for rebels remains low (Fig. 3b). As well, governmental policies keep track of emerging public issues (Fig. 3c) so the polity is operating in a stable mode. Marginal support for rebels can exist but the state has sufficient capacity to deal with issues. 


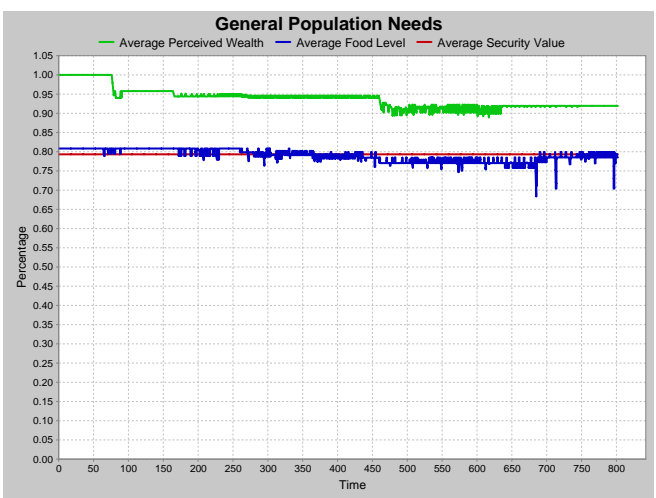

(a) General population needs under a stable scenario.

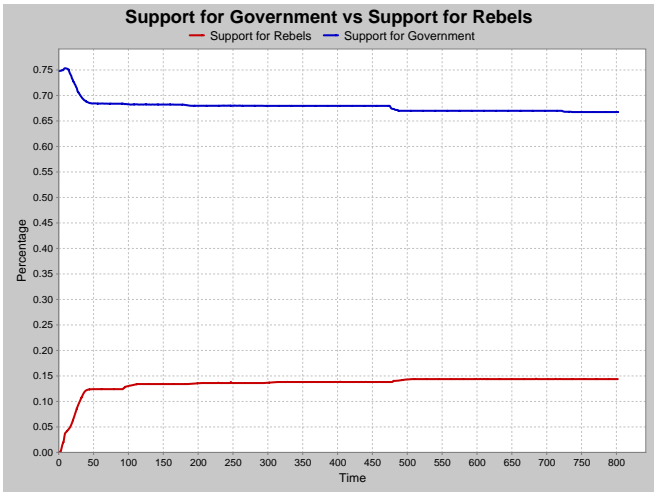

(b) Support for government and support for rebels under a stable scenario.

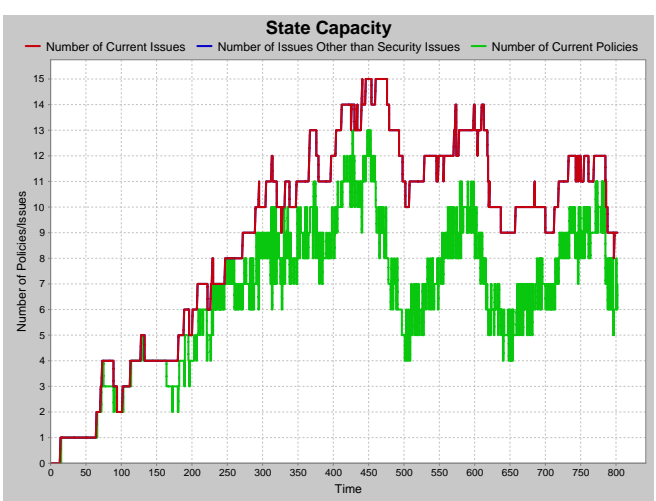

(c) Trends in state capacity under a stable scenario.

Fig. 3. RebeLand simulation run under a "stable" scenario where government has sufficient capacity to manage public issues that arise in the normal life of the polity and public support remains favorable.

\section{B. Contentious scenario (Fig. 4)}

This case shows the general population less satisfied in terms of average perceived wealth, eating less well, and feeling somewhat less secure (Fig. 5a), as in a less stable but still mostly prosperous country. Support for government can remain high but, conversely support for rebels is ocassionally spiked when hunger and poverty begin to take hold (Fig. 5b). In this scenario governmental policies have a harder time keeping track of emerging public issues (Fig. 5c) so the polity is operating in a decreasingly stable (increasingly unstable) mode. Note that support for rebels $(5 \mathrm{~b}$, red) drops back down after each spike, but resettles at slowly rising levels, indicative of a fundamental (diachronic) rift.

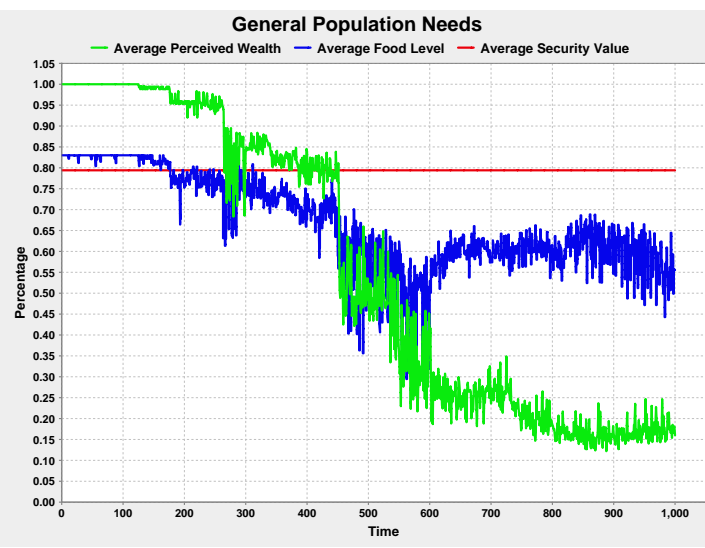

(a) General population needs under a contentious scenario.

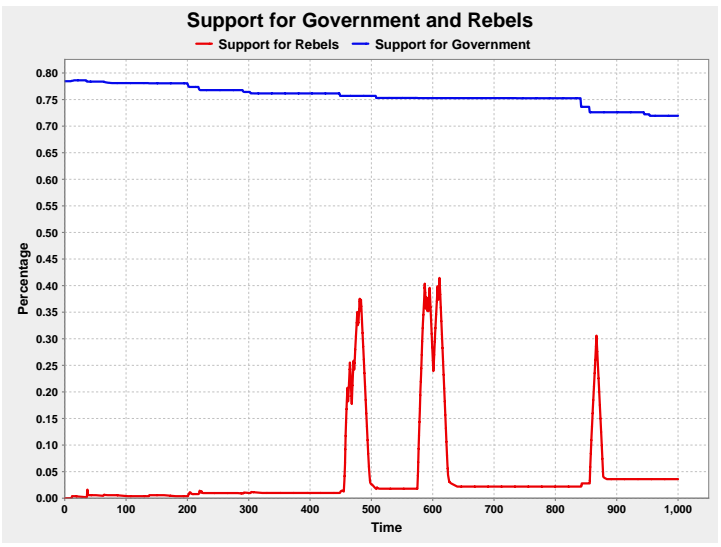

(b) Support for government and support for rebels under a contentious scenario.

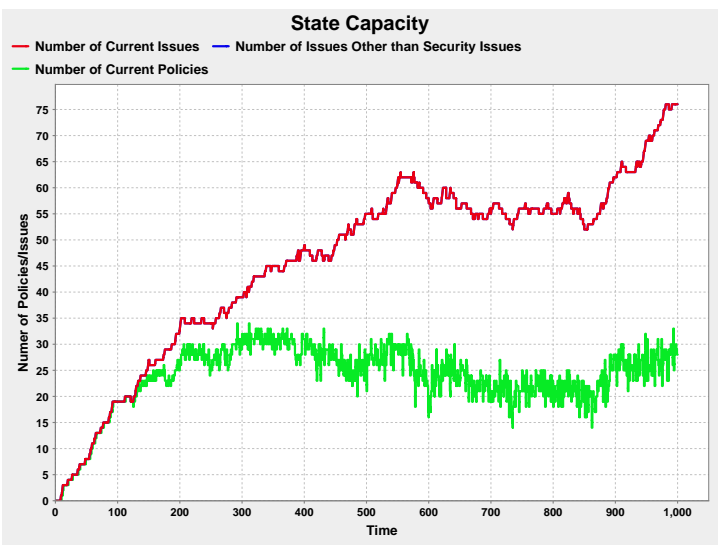

(c) Trends in state capacity under a contentious scenario. 
Fig. 4. RebeLand simulation run under a "contentious" scenario where government still has sufficient capacity to manage public issues that arise in the normal life of the polity but insurgency emerges as a consequence of popular dissatisfaction.

\section{Unstable scenario (state failure, Fig. 5)}

This case shows a more severe decrease in the average perceived wealth of the general population, in addition to eating less well, and feeling significantly less secure (Fig $5 a)$, as in an increasingly unstable polity with dramatically declining prosperity. In this case levels of support for government plummet catastrophically (around time $=325$ ), with a corresponding rise in support for rebels (Fig. 5b). In this unstable scenario governmental policies do not keep track of emerging public issues (Fig. 6c), even when such issues no longer concern security (as shown by the graph of non-security issues in blue on Fig. 6c). This scenario produces state failure as an emergent phenomenon; a consequence of the government being overwhelmed by public issues relative to state capacity and concomitant popular support for rebels.

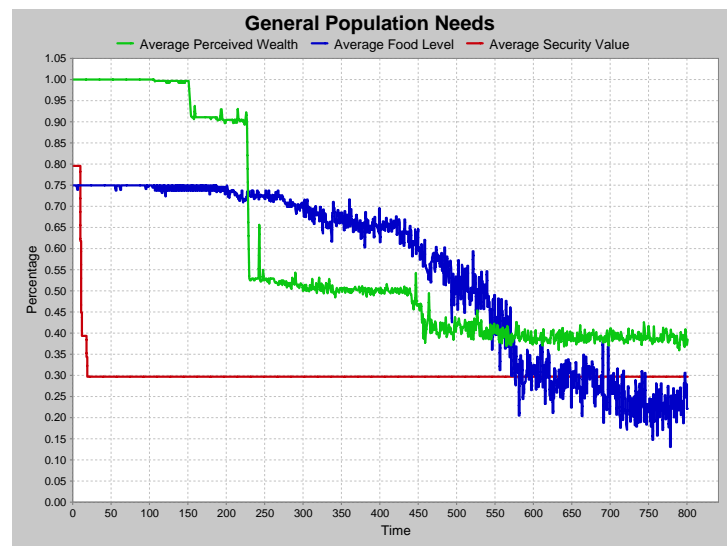

(a) General population needs under an unstable scenario.

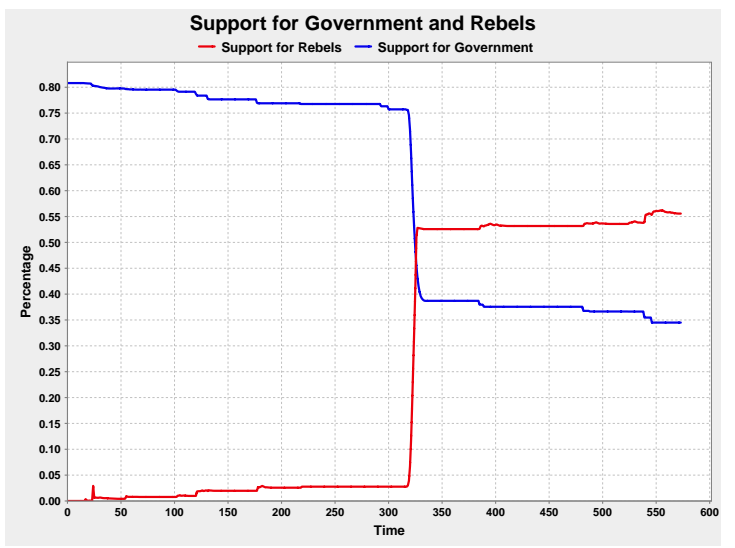

(b) Support for government and support for rebels under an unstable scenario.

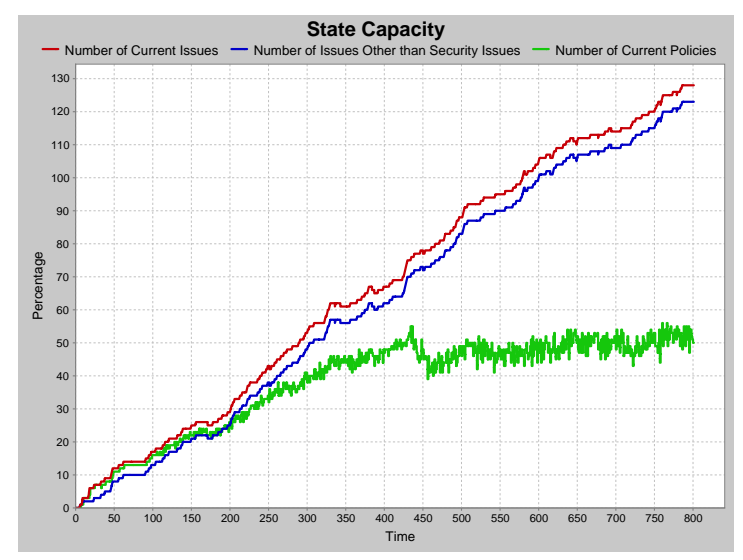

(c) Trends in state capacity under a contentious scenario.

Fig. 5. RebeLand simulation run under an "unstable" scenario where government has insufficient capacity to manage public issues and the emergent insurgency manages to topple the government.

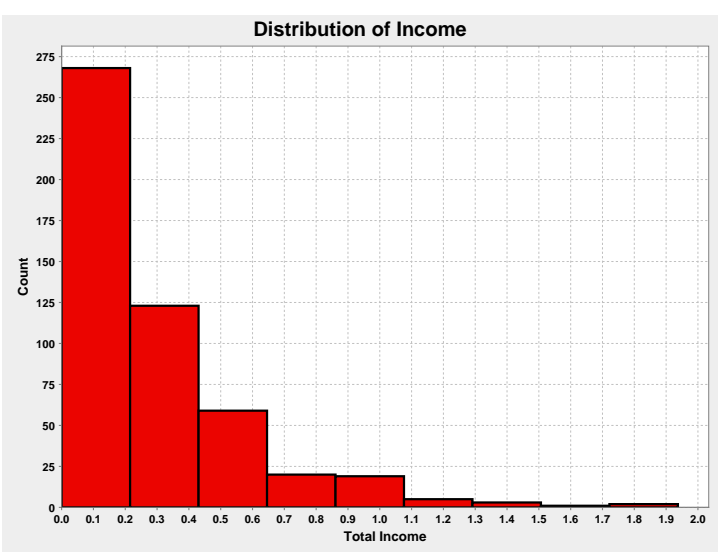

(a) Pareto distribution (power law) of individual agent income.

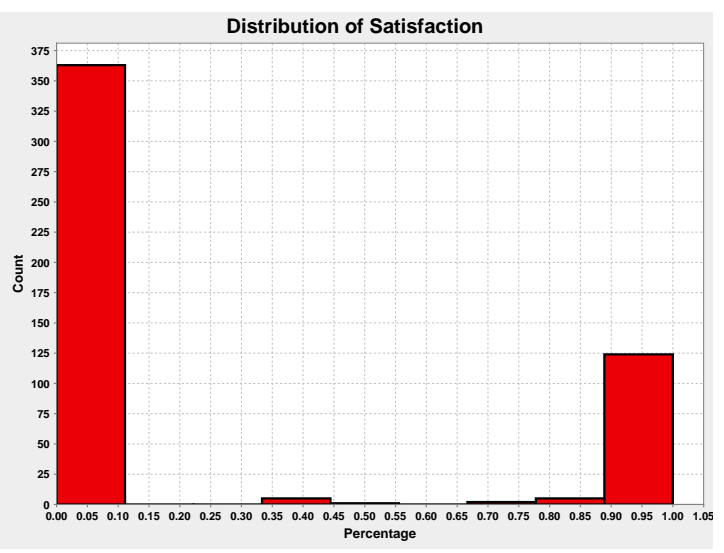

(b) Bimodal distribution of agent satisfaction.

Fig. 6. Individual agent distributions in RebeLand: Income and satisfaction. Source: Prepared by the authors.

Shifts in public moods, insurgency, governmental crises, and state failure all occur as emergent phenomena, not as directly hard-wired processes or events, in all three 
scenarios. RebeLand is universally capable of generating phenomena as a result of its own endogenous dynamics (Epstein 2008).

RebeLand also replicates two empirical patterns (face validity): a Pareto distribution of income (Fig. 6a) and bimodal popular satisfaction (7b).

\section{DISCUSSION}

Our results demonstrate two important points related to the initial research questions that RebeLand was designed to investigate: (1) the state of the polity as a whole responds to levels of societal stress and governmental performance, by remaining stable (scenarios 1 and 2) or in some extreme situations (scenario 3) undergoing regime failure, consistent with contemporary political theory; and (2) the overall political dynamics (insurgency, political instability, and state failure) emerge as "bottom up" phenomena (i.e., are not hard-wired) through complex mechanisms and feedback loops that can be traced down to the perceptions, decisions, and actions of many individual agents in the populations in interaction with government and a natural environment. Many features and processes have yet to be included to approximate a real-world country. But these initial results provide face validity and and solid prospects for further analysis and development.

The MASON RebeLand model, along with other similar agent-based models that inspired it (e.g., Bennett 2009; Bhavnani et al. 2008), contribute to the scientific literature on state stability and failure analysis in at least three ways:

1) the $A B M$ approach enables the formalization of an entire polity in a way that goes well beyond what other types of modeling approaches (statstical or mathematical; game-theoretic or dynamical system) can do. Importantly, this also contributes to social science interdisciplinary integration and the implementation of a whole-system approach.

2) computational simulation modeling enables the experimental analysis of policies and other features that cannot be implemented through earlier approaches. For example, the agent-based modeling approach lends itself to asking many what-if questions of theoretical and practical interest, well beyond what can be accomplished through earlier approaches (e.g., econometric models).
3) spatial agent-based models also permit a viable implementation coupled-socio natural systems and the complex interaction that arise in the normal life of a geographically situated polity. Additionally, this can be done without excluding other non-spatial features, such as social networks, social organizations, or institutions.

\section{CONCLUSIONS}

Computational models of polities and insurgency (civil unrest, guerrilla, violent rebellion) have a research tradition dating back several decades. The MASON RebeLand model presented here offers three innovations: (1) an explicit polity model with politically complete structure and processes; (2) social and natural model components within an integrated socio-natural system; and (3) generative dynamics where insurgency and the state of the polity (stable, unstable, failing, failed, recovering) occur as emergent phenomena under a range of social and environmental conditions, not as predetermined outcomes. Earlier agent-based models (ABMs) on similar topics have been useful in covering parts of RebeLand's scope. Three scenarios are demonstrated, showing stable, unstable, and failing polity conditions. The MASON computational toolkit also permits additional experiments and extensions beyond the initial set reported in this paper.

\section{ACKNOWLEDGEMENTS}

Funding for this study was provided by the Center for Social Complexity of George Mason University and by ONR MURI grant no. N00014-08-1-0921. Thanks to members of the Mason-HRAF Joint Project on Eastern Africa (MURI Team), as well as to Rebecca Goolsby, John Tagney, and Nils B. Weidmann for helpful criticisms and comments. The opinions, findings, and conclusions or recommendations expressed in this work are those of the authors and do not necessarily reflect the views of the sponsors. MASON RebeLand was developed by C. Cioffi-Revilla and M. Rouleau and coded by M. Rouleau.

\section{REFERENCES}

Bennett, Scott D. 2008. Governments, Civilians, and the Evolution of Insurgency: Modeling the Early Dynamics 
of Insurgencies. Journal of Artificial Societies and Social Simulation. 11(4).

Bhavnani, Ravi, Miodownik, Dan, and Nart, Jonas. 2008. REsCape: an Agent-Based Framework for Modeling Resources, Ethnicity, and Conflict. Journal of Artificial Societies and Social Simulation. 11(2).

Cederman, Lars-Erik. 2003. Modeling the size of wars: From billiard balls to sandpiles. American Political Science Review 97 (1):135-150.

Cederman, L.-E. and Girardin, L. 2007 Beyond fractionalization: Mapping ethnicity on nationalist insurgencies. American Political Science Review, 101(1):173-185.

Choucri, N., Goldsmith, D., Madnick, S., Morrison, J. B., and Siegel, M. 2007. Using system dynamics to model and better understand state stability. In 25th International Conference of the System Dynamics Society, Boston, MA.

Cioffi-Revilla, Claudio. 2002. Invariance and universality in social agent-based simulations. Proceedings of the National Academy of Science of the U.S.A. 99 (Supp. 3) (14):7314-7316.

Cioffi-Revilla, Claudio. 2009. Simplicity and Reality in Computational Modeling of Politics. Computational and Mathematical Organization Theory 15: 26-46.

Cioffi-Revilla, Claudio, and Nicholas M. Gotts. 2003. Comparative analysis of agent-based social simulations: GeoSim and FEARLUS models. Journal of Artificial Societies and Social Simulation 6 (4).

Cioffi-Revilla, Claudio, and Mark Rouleau. 2009. MASON RebeLand: An Agent-Based Model of Politics, Environment, and Insurgency. Proceedings of the Annual Convention of the International Studies Association, New York, February 15-18, 2009.

Cioffi-Revilla, Claudio, Sean Paus, Sean Luke, James L. Olds, and Jason Thomas. 2004. Mnemonic Structure and Sociality: A Computational Agent-Based Simulation Model. In Proceedings of the Agent 2004 Conference on Social Dynamics: Interaction, Reflexivity and Emergence, edited by D. Sallach and C. Macal. Chicago, IL: Argonne National Laboratory and University of Chicago.

Cioffi-Revilla, Claudio, Sean Luke, Dawn C. Parker, J. Daniel Rogers, William W. Fitzhugh, William Honey- church, Bruno Frohlich, Paula DePriest, and Chunag Amartuvshin. 2007. Agent-based Modeling Simulation of Social Adaptation and Long-Term Change in Inner Asia. In Advancing Social Simulation: The First World Congress in Social Simulation, edited by T. Terano and D. Sallach. Tokyo, New York, and Heidelberg: Springer Verlag.

De Rouen Jr., Karl R. and Sobek, David. 2004. The Dynamics of Civil War Duration and Outcome. Journal of Peace Research, 41(3):303-320.

Doran, Jim. 2005. Iruba: An Agent-Based Model of Guerrilla War Process. In Representing Social Reality, Pre-proceedings of the Third Conference of the European Social Simulation Association (ESSA):198-205.

Epstein, Joshua. 2006. Generative Social Science: Studies in Agent-Based Computational Modeling. Princeton, NJ: Princeton University Press.

Fearon, James D. and Laitin, David, D. 2003. Ethnicity, Insurgency, and Civil War, American Political Science Review 97(1).

Gurr, T. R.. 1970. Why Men Rebel. Princeton, New Jersey: Princeton University Press.

Ilachinski, A. 2004. Artificial War: Multi-Agent Based Simulation of Combat. World Scientific. Singapore.

Kalyvas, Stathis N. 2006. The Logic of Violence in Civil War. Cambridge University Press.

King, Gary, and Langche Zeng. 2001. Improving Forecasts of State Failure. World Politics 53:623-58.

Luke, Sean, Claudio Cioffi-Revilla, Liviu Panait, and Keith Sullivan. 2005. MASON: A Java Multi-Agent Simulation Environment. Simulation: Transactions of the Society for Modeling and Simulation International 81 (7):517-527.

Lustick, Ian S. 2000. Agent-based modelling of collective identity: testing constructivist theory. Journal of Artificial Societies and Social Simulation 3(1). Available online.

Turchin, Peter. 2003. Historical Dynamics: Why States Rise and Fall. Princeton, NJ: Princeton University Press. 